\title{
Probabilistic Assessment of Degree of Bending in Tubular X-Joints of Offshore Structures Subjected to Bending Loads
}

\author{
Hamid Ahmadi and Amirreza Ghaffari \\ Faculty of Civil Engineering, University of Tabriz, Tabriz 5166616471, Iran \\ Correspondence should be addressed to Hamid Ahmadi; h-ahmadi@tabrizu.ac.ir
}

Received 23 November 2014; Revised 13 February 2015; Accepted 15 February 2015

Academic Editor: S. T. Quek

Copyright (C) 2015 H. Ahmadi and A. Ghaffari. This is an open access article distributed under the Creative Commons Attribution License, which permits unrestricted use, distribution, and reproduction in any medium, provided the original work is properly cited.

\begin{abstract}
Fatigue life of tubular joints in offshore structures is significantly influenced by the degree of bending (DoB). The DoB exhibits considerable scatter calling for greater emphasis in accurate determination of its governing probability distribution which is a key input for the fatigue reliability analysis of a tubular joint. Although the tubular X-joints are commonly found in offshore jacket structures, as far as the authors are aware, no comprehensive research has been carried out on the probability distribution of the $\mathrm{DoB}$ in tubular X-joints. In the present paper, results of parametric equations available for the calculation of the DoB have been used to develop probability distribution models for the DoB in the chord member of tubular X-joints subjected to four types of bending loads. Based on a parametric study, a set of samples was prepared and density histograms were generated for these samples using Freedman-Diaconis method. Twelve different probability density functions (PDFs) were fitted to these histograms. In each case, Kolmogorov-Smirnov test was used to evaluate the goodness of fit. Finally, after substituting the values of estimated parameters for each distribution, a set of fully defined PDFs have been proposed for the DoB in tubular X-joints subjected to bending loads.
\end{abstract}

\section{Introduction}

Offshore jacket-type platforms are mainly fabricated with circular hollow section (CHS) members. The intersection between CHS members is called a tubular joint. Figure 1 shows a tubular X-joint along with the three commonly named positions along the brace/chord intersection: saddle, crown toe, and crown heel. Nondimensional geometrical parameters including $\alpha, \beta, \gamma, \tau$, and $\alpha_{B}$ which are used to feasibly relate the behavior of a tubular joint to its geometrical characteristics are defined in Figure 1.

Tubular joints are subjected to wave induced cyclic loads and thus are susceptible to fatigue damage. The stress-life ( $S$ $N$ ) approach, based on the hot-spot stress (HSS), is widely used to estimate the fatigue life of the joint. The HSS can be calculated through the multiplication of nominal stress by the stress concentration factor (SCF). However, the investigation of a large number of fatigue test results has shown that tubular joints with different geometry or loading type but with similar HSSs often can endure significantly different numbers of cycles before failure [1]. These differences are thought to be attributable to changes in crack growth rate which is dependent on the through-the-thickness stress distribution as well as the HSS. The stress distribution across the wall thickness is assumed to be a linear combination of membrane and bending stresses. It can be characterized by the degree of bending (DoB), that is, the ratio of bending stress to total stress.

As mentioned before, it has become evident that the HSS is not enough to characterize all aspects of fatigue failure. Therefore, the standard stress-life approach may be unconservative for the joints with low DoB. Hence, the current standard HSS-based $S-N$ approach can be modified to include the effect of the DoB representing the throughthe-thickness stress distribution in the tubular joint in order to reduce the scatter in the $S-N$ curve and to obtain more accurate fatigue life prediction. The other shortcoming of the $S-N$ approach is that this method gives only the total life and cannot be used to predict fatigue crack growth and the remaining life of cracked joints. For the fatigue analysis of cracked joints, fracture mechanics (FM) should be used. The accurate determination of a stress intensity factor (SIF) 


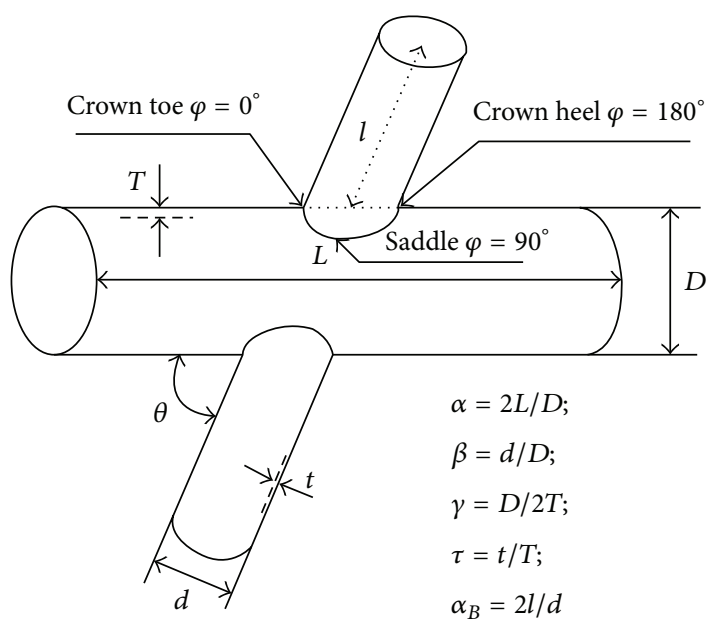

Figure 1: Geometrical notation for a tubular X-joint.

is the key for FM calculations. It is well known that it is necessary to take the complex stress field in tubular welded joints into account to have accurate SIF data. Owing to the complexities introduced by the structural geometry and the nature of the local stress fields, it is impossible to calculate the SIFs analytically. This problem is often tackled by using the simplified models, such as the flat plate solution or TButt weight function based method, with an appropriate load shedding model. In order to use these simplified SIF models to calculate the remaining fatigue life of tubular joints, the information is required again on the distribution of throughthe-thickness stress acting in the anticipated crack path, which can be characterized by the DoB. Thus, the DoB is an important input parameter for the calculation of fatigue crack growth in tubular welded joints.

Deterministic fatigue analyses typically produce conservative results, since limiting assumptions are to be made on key input parameters. Some of the key parameters of the problem can exhibit stochastic behavior. This highlights the necessity of conducting a reliability analysis in which these key parameters can be modeled as random quantities. The fundamentals of reliability assessment, if properly applied, can provide immense insight into the performance and safety of the structural system. Under any specific loading condition, the DoB value in a tubular joint is mainly determined by the joint geometry and exhibits considerable scatter calling for greater emphasis in accurate determination of its governing probability distribution which is an essential input for the fatigue reliability analysis of a tubular joint. As far as the authors are aware, despite the considerable research work accomplished on the study of SCFs and SIFs in tubular joints and a few projects defined about the deterministic analysis of the DoB (see the next paragraph), no comprehensive research has been carried out on the probability distribution of the DoB in tubular joints. What has been used so far as the probability distribution of the $\mathrm{DoB}$ in the fatigue reliability analysis of offshore structures is mainly based on assumptions and limited observations, especially in terms of distribution parameters.
Bowness and Lee [2] investigated the fatigue crack curvature under the weld toe in an offshore tubular joint. Lee et al. [3] numerically studied the cracked tubular T-, Y-, and K-joints under combined loads. Shao [4] analyzed the stress intensity factor (SIF) for cracked tubular K-joints subjected to balanced axial load. Wordsworth and Smedley [5] studied stress concentrations at unstiffened tubular joints. Efthymiou [6] developed a set of SCF formulae and generalized influence functions for use in fatigue analysis. Chang and Dover [7] proposed parametric equations to predict stress distributions along the intersection of tubular X- and DT-joints. Lotfollahi-Yaghin and Ahmadi [8] investigated geometric stress distribution along the weld toe of the outer brace in two-planar tubular DKT-joints. Ahmadi and LotfollahiYaghin [9] performed a geometrically parametric study on central brace SCFs in offshore three-planar tubular KT-joints. Ahmadi et al. [10] studied chord-side SCF distribution of central brace in internally ring-stiffened tubular KT-joints. A series of systematic thin shell FE analyses were carried out by Chang and Dover [11] for 330 tubular X- and DTjoints typical of those found in offshore structures, under six different types of loading. Mean and design equations for DoBs at critical positions in axially loaded tubular Kjoints were derived by Morgan and Lee [12] from a previously established FE database of 254 joints. Design equations met all the acceptance criteria recommended by the UK DoE [13]. Lee and Bowness [14] proposed an engineering methodology for estimating SIF solutions for semielliptical weld-toe cracks in tubular joints. The SIFs for a grouted tubular joint were determined both numerically and empirically by Shen and Choo [15].

In the present paper, results of parametric equations available for the calculation of the DoB have been used to propose probability distribution models for the DoB in the chord member of tubular X-joints subjected to four different types of bending loads including single and double in-plane bending (IPB) and out-of-plane bending (OPB) loadings (Figure 2). Based on a parametric study, a set of samples was prepared and density histograms were generated for these samples using Freedman-Diaconis method. Twelve different probability density functions (PDFs) were fitted to these histograms. The maximum likelihood (ML) method was used to determine the parameters of fitted distributions. In each case, Kolmogorov-Smirnov test was used to evaluate the goodness of fit. Finally, after substituting the values of estimated parameters in distribution models, a set of fully defined PDFs have been proposed for the DoB in tubular Xjoints under bending loads.

\section{DoB in Tubular X-Joints Subjected to Bending Loads}

As mentioned earlier, the degree of bending $(\mathrm{DoB})$ is the ratio of bending stress over total stress expressed as

$$
\mathrm{DoB}=\frac{\sigma_{B}}{\sigma_{T}}=\frac{\sigma_{B}}{\sigma_{B}+\sigma_{M}},
$$




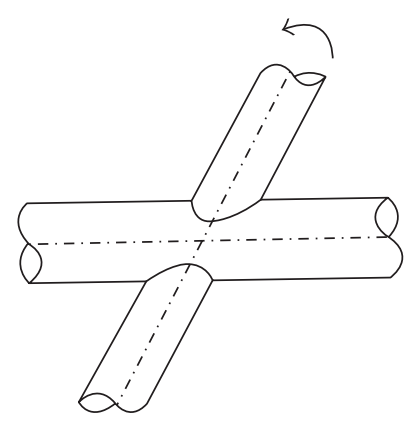

1st loading condition (single IPB)

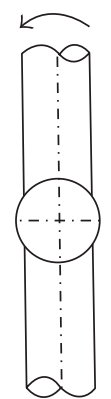

2nd loading condition (single OPB)

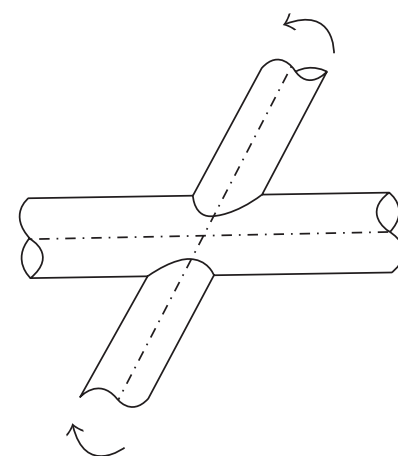

3rd loading condition (double IPB)

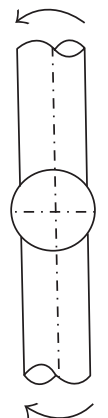

4th loading condition (double OPB)

FIGURE 2: Considered loading conditions.

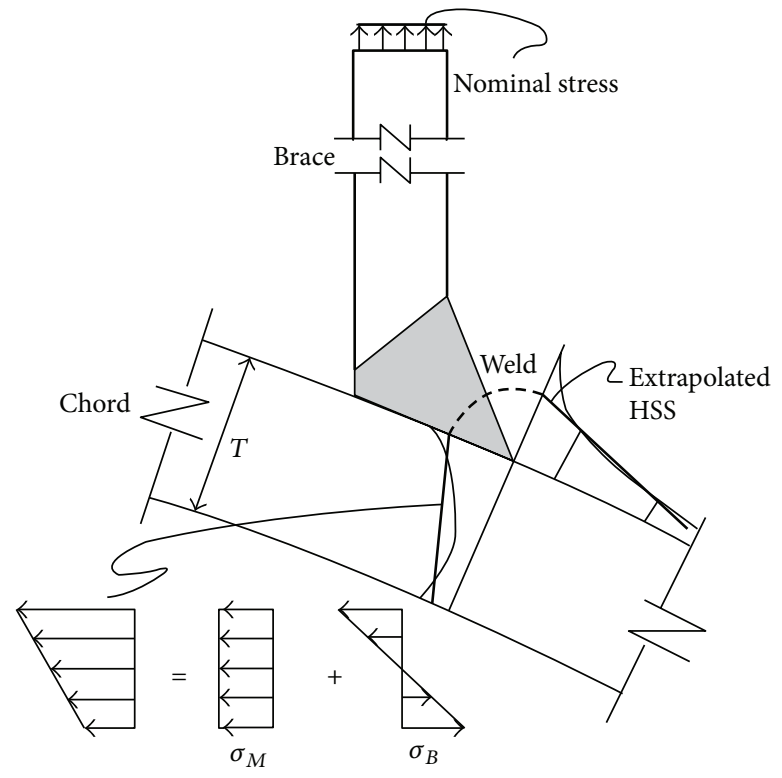

FIGURE 3: Linearized through-the-thickness stress distribution.

where $\sigma_{B}$ and $\sigma_{M}$ are the bending and membrane stress components and $\sigma_{T}$ is the total stress on the outer surface of the chord (Figure 3).

Chang and Dover [11] proposed a set of equations for the calculation of the DoB of the chord member in tubular $\mathrm{X}$-joints subjected to bending loads (2). In these equations, the DoB is corresponding to the position of the HSS, that is, the position in which the maximum SCF occurs. $\mathrm{DoB}_{\mathrm{S}-\mathrm{IPB}}$, $\mathrm{DoB}_{\mathrm{S}-\mathrm{OPB}}, \mathrm{DoB}_{\mathrm{D}-\mathrm{IPB}}$, and $\mathrm{DoB}_{\mathrm{D}-\mathrm{OPB}}$ denote the $\mathrm{DoB}$ under the single IPB, single OPB, double IPB, and double OPB loadings, respectively (Figure 2), and $\mathrm{DoB}^{+}$and $\mathrm{DoB}^{-}$stand for the $\mathrm{DoB}$ at the positive and negative HSS positions. It should be noted that single IPB and single OPB loadings can actually occur in a tubular joint of an offshore jacket structure depending on the wave incident angle, location of the joint, relative position of the wave crest, and design load combination. In such loading cases, the single IPB/OPB moment is balanced by the internal forces of the chord member instead of the other brace member

$$
\begin{aligned}
& \mathrm{DoB}_{\text {S-IPB }}^{-}=\exp \left(-0.7153+0.654 \sin \theta-1.491 \beta^{5}\right. \\
& +0.00129 \frac{\alpha}{\theta}+0.00832 \beta \gamma \tau^{2}-0.123 \frac{\beta}{\theta} \\
& +0.00316 \frac{\gamma}{\theta}-0.000004 \gamma^{4}-0.2 \sin ^{2} \theta \\
& +1.19 \beta^{4}+\frac{0.01261}{\beta^{2}} \\
& \left.-0.0009 \frac{\gamma}{\beta^{2}}+0.0001 \frac{\gamma^{2}}{\beta}\right), \\
& \mathrm{DoB}_{\text {S-IPB }}^{+}=0.7924-0.0661 \frac{\ln \beta}{\theta}+0.00963 \beta \gamma \tau^{2} \\
& -0.1192 \frac{\ln \gamma}{\theta}-0.0428 \tau^{4}-0.209 \beta^{5} \\
& -0.536 \ln (\sin \theta)-0.0126 \gamma+0.0068 \beta^{2} \gamma \\
& -0.056 \ln \beta-0.000004 \gamma^{4}+0.00071 \gamma^{2} \\
& -0.2 \ln \theta+0.262 \sin ^{2} \theta+0.00082 \alpha, \\
& \mathrm{DoB}_{\mathrm{S}-\mathrm{OPB}}=\exp (0.092972-0.1492 \sin \theta-0.1593 \beta \\
& +0.00269 \beta \gamma \tau^{2}+0.0392 \frac{\beta}{\theta} \\
& \left.-0.0136 \frac{\tau}{\theta}-0.00104 \frac{\gamma}{\theta}+0.00002 \gamma^{2}\right), \\
& \mathrm{DoB}^{-}{ }_{\mathrm{D}-\mathrm{IPB}}=\exp (-1.2643-0.0184 \gamma \tau+1.67 \sin \theta \\
& +0.0149 \beta \gamma \tau^{2}+0.00264 \frac{\gamma}{\theta}-0.0655 \beta^{2} \gamma \tau \\
& -0.885 \sin ^{2} \theta+\frac{0.0057}{\beta^{2}}+0.057 \beta \gamma \tau
\end{aligned}
$$


TABLE 1: Values of statistical measures for the DoB samples.

\begin{tabular}{|c|c|c|c|c|c|c|}
\hline \multirow{2}{*}{ Statistical measure } & \multicolumn{6}{|c|}{ Sample } \\
\hline & $\mathrm{DoB}_{\text {S-IPB }}^{-}$ & $\mathrm{DoB}_{S-\mathrm{IPB}}^{+}$ & $\mathrm{DoB}_{\mathrm{S}-\mathrm{OPB}}$ & $\mathrm{DoB}_{\text {D-IPB }}^{-}$ & $\mathrm{DoB}_{\text {D-IPB }}^{+}$ & $\mathrm{DoB}_{\mathrm{D}-\mathrm{OPB}}$ \\
\hline$n$ & 3125 & 3125 & 625 & 3125 & 243 & 625 \\
\hline$\mu$ & 0.4220 & -0.6714 & 0.9054 & 0.8171 & 0.5890 & 0.8983 \\
\hline$\sigma$ & 0.3050 & 1.65 & 0.0274 & 0.0747 & 0.2002 & 0.0337 \\
\hline$\alpha_{3}$ & -0.0633 & -0.9183 & -0.1602 & -0.2505 & 0.0183 & -0.2918 \\
\hline$\alpha_{4}$ & 1.4590 & 2.3547 & 2.3787 & 2.9113 & 2.2840 & 3.2364 \\
\hline
\end{tabular}

$$
\begin{aligned}
& +0.091 \frac{\tau}{\theta}+0.127 \theta+0.00024 \alpha \gamma \\
& \left.+0.0018 \frac{\alpha}{\theta}-0.00012 \alpha^{2}\right),
\end{aligned}
$$

$\mathrm{DoB}^{+}{ }_{\text {D-IPB }}=1.521+0.00063 \alpha \gamma+0.011392 \beta^{2} \gamma \tau$

$$
\begin{aligned}
& -1.116 \sin \theta-0.079 \frac{\beta}{\theta}-0.0053 \frac{\gamma}{\theta} \\
& +\frac{0.00551}{\beta^{2}}+0.00011 \gamma^{2}-0.0129 \beta^{3} \gamma \\
& -0.00005 \frac{\gamma^{2}}{\beta}+0.575 \sin ^{2} \theta \\
& -0.083 \theta-0.00012 \alpha^{2}+\frac{25}{\gamma^{3}}-0.0078 \alpha, \\
\mathrm{DoB}_{\mathrm{D}-\mathrm{OPB}}= & 0.8388-0.0183 \frac{\ln \beta}{\theta}+0.00215 \beta \gamma \tau^{2} \\
& -0.2123 \beta^{5}+0.00475 \beta^{2} \gamma \\
& -0.00003 \gamma^{2}-0.0371 \ln \beta \\
& -0.0433 \ln (\sin \theta)-0.0052 \frac{\ln \tau}{\theta} .
\end{aligned}
$$

The validity ranges for the application of (2) are as follows:

$$
\begin{aligned}
& 6.0 \leq \alpha \leq 40.0, \\
& 0.2 \leq \beta \leq 0.8, \\
& 7.6 \leq \gamma \leq 32.0, \\
& 0.2 \leq \tau \leq 1.0, \\
& 35^{\circ} \leq \theta \leq 90^{\circ} .
\end{aligned}
$$

\section{Preparation of the DoB Samples}

A MATLAB code was developed to generate six samples for the DoB based on (2). These equations have five variables including $\alpha, \beta, \gamma, \tau$, and $\theta$. Developed MATLAB code divided the validity range for each parameter (3) into equal intervals and calculated the DoB for all possible combinations of the boundary values. For example, to generate the $\mathrm{DoB}^{-}$S-IPB sample, developed code calculated the DoB for all possible combinations of five values of $\alpha(6,14.5,23,31.5$, and 40$)$, five values of $\beta(0.2,0.35,0.5,0.65$, and 0.8$)$, five values of $\gamma(7.6$, $13.7,19.8,25.9$, and 32$)$, five values of $\tau(0.2,0.4,0.6,0.8$, and $1.0)$, and five values of $\theta\left(35^{\circ}, 48.75^{\circ}, 62.5^{\circ}, 76.25^{\circ}\right.$, and $\left.90^{\circ}\right)$ which led to $3125\left(5^{5}\right)$ data points for this sample.

Values of the size $(n)$, mean $(\mu)$, standard deviation $(\sigma)$, coefficient of skewness $\left(\alpha_{3}\right)$, and coefficient of kurtosis $\left(\alpha_{4}\right)$ for generated samples are listed in Table 1.

The value of $\alpha_{3}$ for $\mathrm{DoB}_{\text {S-IPB }}^{-}, \mathrm{DoB}_{\mathrm{S}-\mathrm{IPB}}, \mathrm{DoB}_{\mathrm{S}-\mathrm{OPB}}$, $\mathrm{DoB}^{-}{ }_{\mathrm{D}-\mathrm{IPB}}$, and $\mathrm{DoB}_{\mathrm{D}-\mathrm{OPB}}$ samples is negative meaning that in these cases; the distribution is expected to have a longer tail on the left, which is toward decreasing values, than on the right. However, the $\mathrm{DoB}^{+}{ }_{\mathrm{D}-\mathrm{IPB}}$ sample has a positive $\alpha_{3}$ value which means that its distribution is expected to have a longer tail on the right. Moreover, in $\mathrm{DoB}^{-}{ }_{\mathrm{S}-\mathrm{IPB}}$, $\mathrm{DoB}^{+}{ }_{\text {S-IPB }}, \mathrm{DoB}_{\mathrm{S}-\mathrm{OPB}}, \mathrm{DoB}^{-}{ }_{\mathrm{D}-\mathrm{IPB}}$, and $\mathrm{DoB}^{+}{ }_{\mathrm{D}-\mathrm{IPB}}$ samples, the value of $\alpha_{4}$ is smaller than three which means that, in these cases, the probability distribution is expected to be mild-peak (platykurtic). On the contrary, in $\mathrm{DoB}_{\mathrm{D}-\mathrm{OPB}}$ sample, the value of $\alpha_{4}$ is greater than three meaning that, in this case, a sharppeak (leptokurtic) probability distribution is to be expected.

\section{Generation of the Density Histograms}

For generating a density histogram, the range $(R)$ should be divided into a number of classes/cells/bins. The number of occurrences in each class is counted and tabulated. These are called frequencies. Then, the relative frequency of each class can be obtained through dividing its frequency by the sample size. Afterwards, the density is calculated for each class through dividing the relative frequency by the class width. The width of classes is usually made equal to facilitate interpretation.

Care should be exercised in the choice of the number of classes $\left(n_{c}\right)$. Too few will cause an omission of some important features of the data; too many will not give a clear overall picture because there may be high fluctuations in the frequencies. In the present research, Freedman-Diaconis rule was adapted to determine the number of classes:

$$
n_{c}=\frac{R\left(n^{1 / 3}\right)}{2(\mathrm{IQR})},
$$

where $R$ is the range of sample data, $n$ is the sample size, and IQR is the interquartile range calculated as follows:

$$
\mathrm{IQR}=Q_{3}-Q_{1}
$$




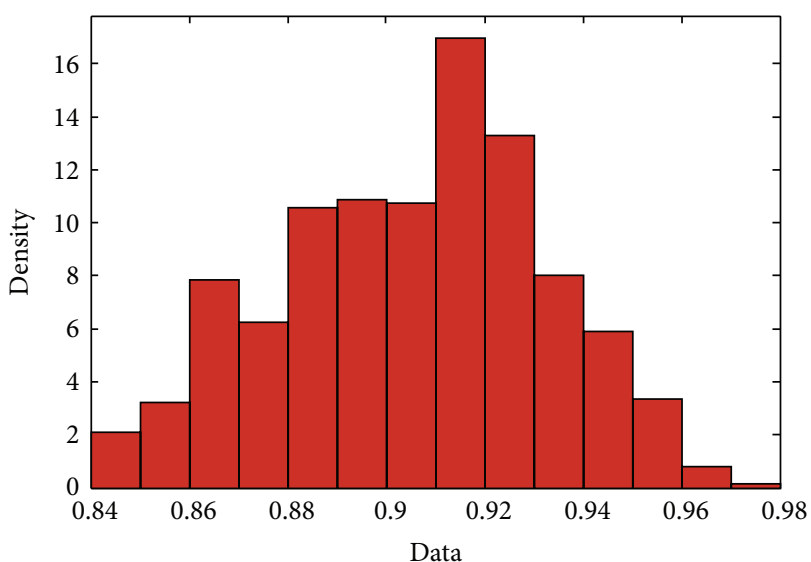

- (DoB)hs data

(a)

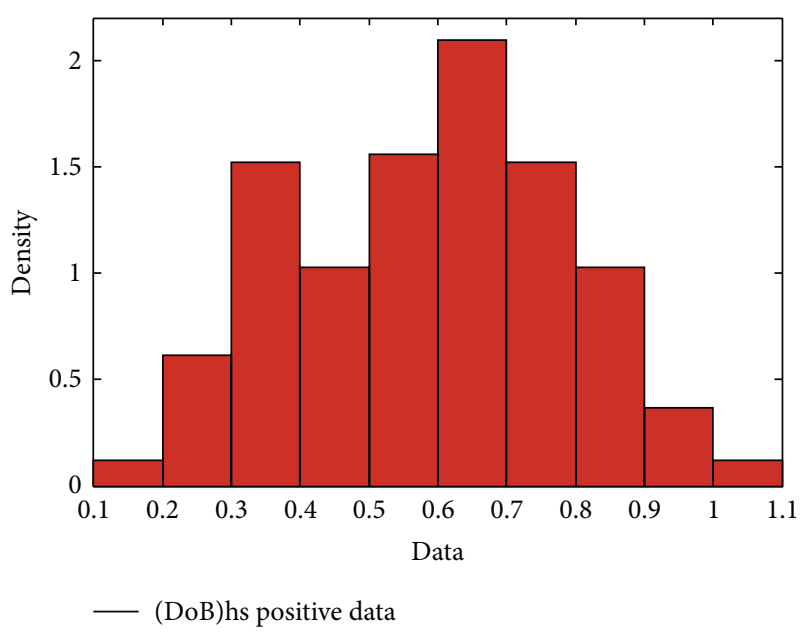

(c)

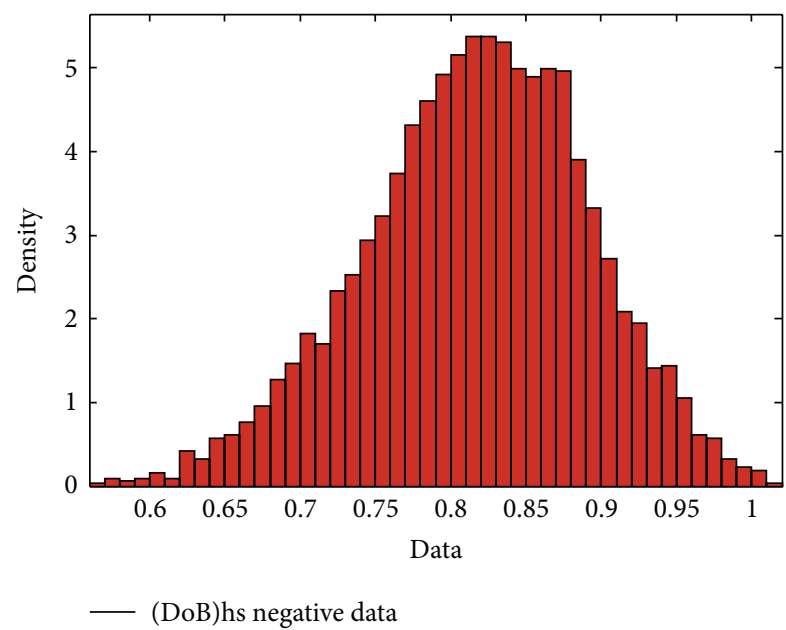

(b)

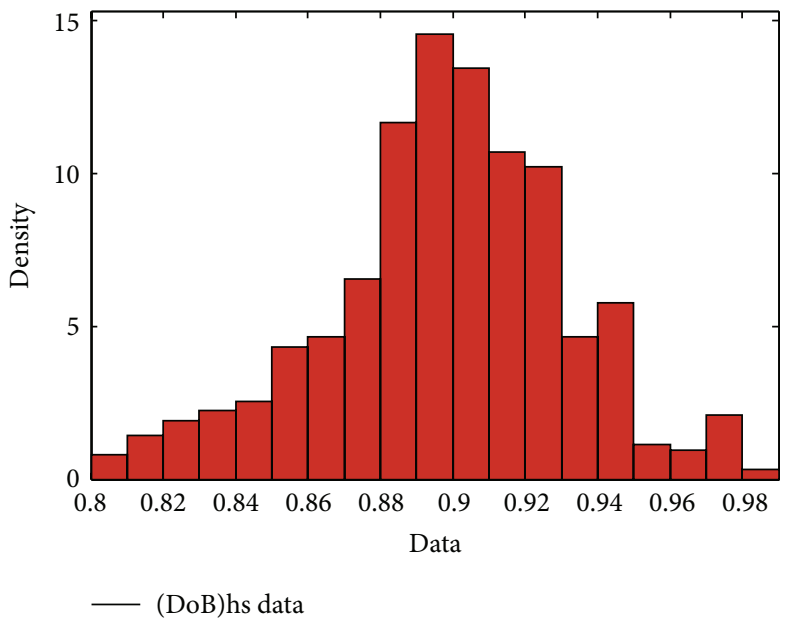

(d)

Figure 4: Generated histograms for DoB samples: (a) $\mathrm{DoB}_{\mathrm{S}-\mathrm{OPB}}$, (b) $\mathrm{DoB}^{-}{ }_{\mathrm{D}-\mathrm{IPB}}$, (c) $\mathrm{DoB}^{+}{ }_{\mathrm{D}-\mathrm{IPB}}$, and (d) $\mathrm{DoB}_{\mathrm{D}-\mathrm{OPB}}$.

where $Q_{1}$ is the lower quartile which is the median of the lower half of the data and, likewise, $Q_{3}$ is the upper quartile that is the median of the upper half of the data.

For example, density histograms of $\mathrm{DoB}_{\mathrm{S}-\mathrm{OPB}}$, $\mathrm{DoB}^{-}{ }_{\mathrm{D}-\mathrm{IPB}}$, $\mathrm{DoB}^{+}{ }_{\mathrm{D}-\mathrm{IPB}}$, and $\mathrm{DoB}_{\mathrm{D}-\mathrm{OPB}}$ samples are shown in Figure 4. As it was expected from values of $\alpha_{3}$ and $\alpha_{4}$ (Table 1), histograms of (a), (b), and (d) have a longer tail on the left than on the right, while the histogram of (c) has a longer tail on the right. It can also be seen that histograms of (a), (b), and (c) are platykurtic; while the histogram of (d) is leptokurtic.

\section{Application of Maximum Likelihood Method for PDF Fitting}

In order to investigate the degree of fitting of various distributions to the sample data, twelve different PDFs were fitted to the generated histograms. For example, PDFs fitted to density histograms of $\mathrm{DoB}_{\mathrm{S}-\mathrm{OPB}}, \mathrm{DoB}^{-}{ }_{\mathrm{D}-\mathrm{IPB}}, \mathrm{DoB}^{+}{ }_{\mathrm{D}-\mathrm{IPB}}$, and $\mathrm{DoB}_{\mathrm{D}-\mathrm{OPB}}$ samples are shown in Figure 5.
In each case, distribution parameters were estimated using the maximum likelihood (ML) method. Results are given in Table 2. It should be noted that none of the considered distributions was acceptably fitted to the $\mathrm{DoB}^{-}{ }_{\text {S-IPB }}$ and $\mathrm{DoB}^{+}{ }_{\text {S-IPB }}$ samples. Hence, no data is provided for these two samples in Table 2.

The ML procedure is an alternative to the method of moments. As a means of finding an estimator, statisticians often give it preference. For a random variable $X$ with a known PDF, $f_{X}(x)$, and observed values $x_{1}, x_{2}, \ldots, x_{n}$, in a random sample of size $n$, the likelihood function of $\theta$, where $\theta$ represents the vector of unknown parameters, is defined as

$$
L(\theta)=\prod_{i=1}^{n} f_{X}\left(x_{i} \mid \theta\right) .
$$

The objective is to maximize $L(\theta)$ for the given data set. This is easily done by taking $m$ partial derivatives of $L(\theta)$, where $m$ is the number of parameters, and equating them tozero. Then the maximum likelihood estimators (MLEs) of 


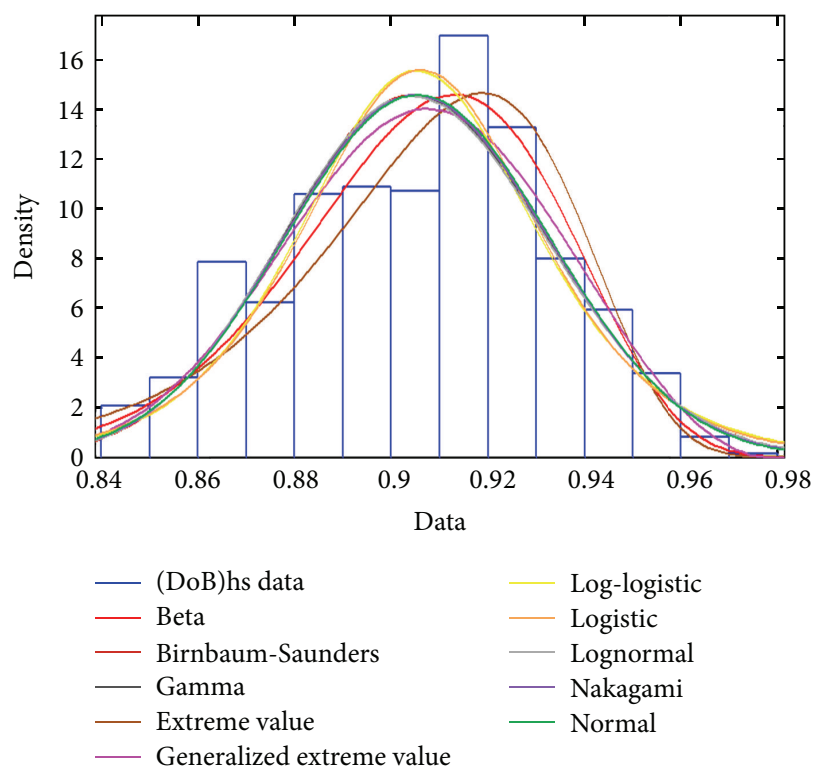

(a)

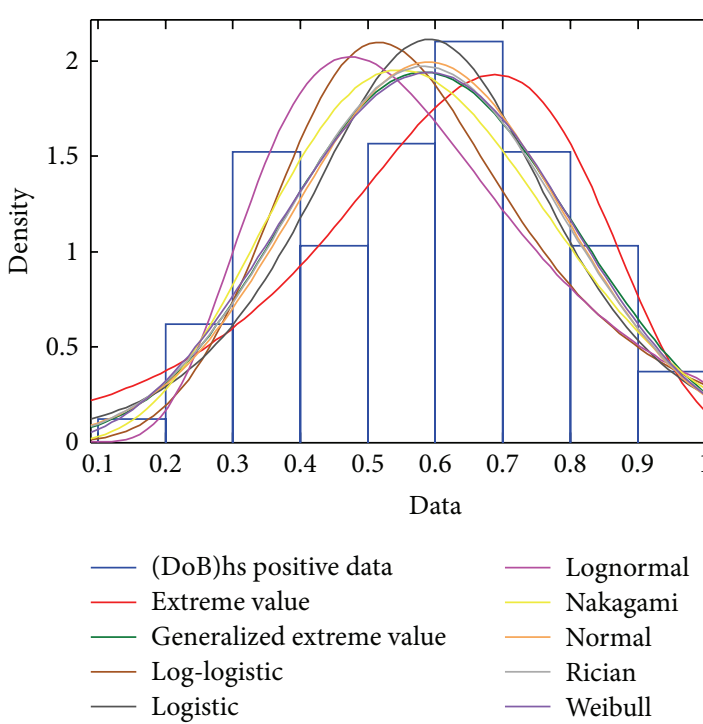

(c)
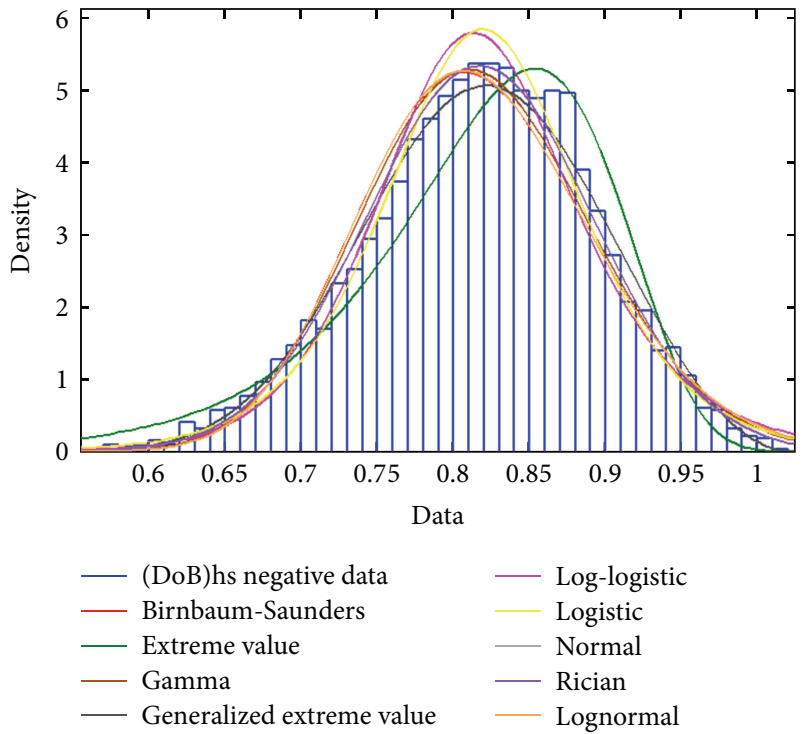

(b)
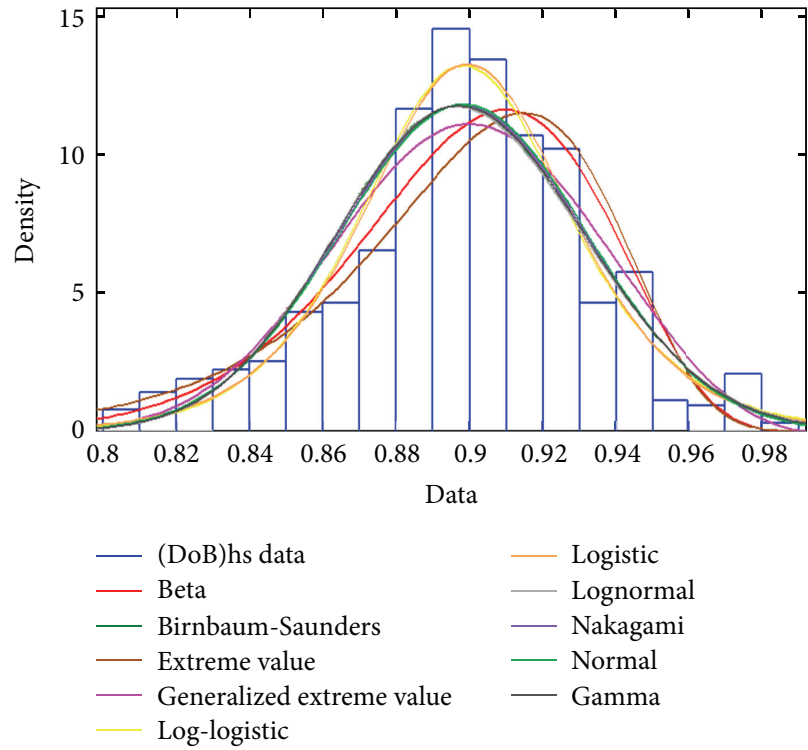

(d)

Figure 5: PDFs fitted to the generated histograms of DoB samples: (a) $\mathrm{DoB}_{\mathrm{S}-\mathrm{OPB}}$, (b) $\mathrm{DoB}^{-}{ }_{\mathrm{D}-\mathrm{IPB}}$, (c) $\mathrm{DoB}^{+}{ }_{\mathrm{D}-\mathrm{IPB}}$, and (d) $\mathrm{DoB}_{\mathrm{D}-\mathrm{OPB}}$.

the parameter set $\theta$ are found by solving the equations. In this way, the greatest probability is given to the observedset of events, provided that the true form of the probability distribution is known.

\section{Using Kolmogorov-Smirnov Test to Evaluate the Goodness of Fit}

The Kolmogorov-Smirnov goodness-of-fit test is a nonparametric test based on the cumulative distribution function (CDF) of a continuous variable. It is not applicable to discrete variables. The test statistic, in a two-sided test, is the maximum absolute difference (i.e., usually the vertical distance) between the empirical and hypothetical CDFs. For a continuous variate $X$, let $x_{(1)}, x_{(1)}, \ldots, x_{(n)}$ represent the order statistics of a sample of the size $n$, that is, the values arranged in increasing order. The empirical or sample distribution function $F_{n}(x)$ is a step function. This gives the proportion of values not exceeding $x$ and is defined as

$$
F_{n}(x)= \begin{cases}0, & \text { For } x<x_{(1)} \\ \frac{k}{n}, & \text { For } x_{(k)} \leq x<x_{(k+1)} \quad k=1,2, \ldots, n-1 \\ 1, & \text { For } x \geq x_{(n)} .\end{cases}
$$




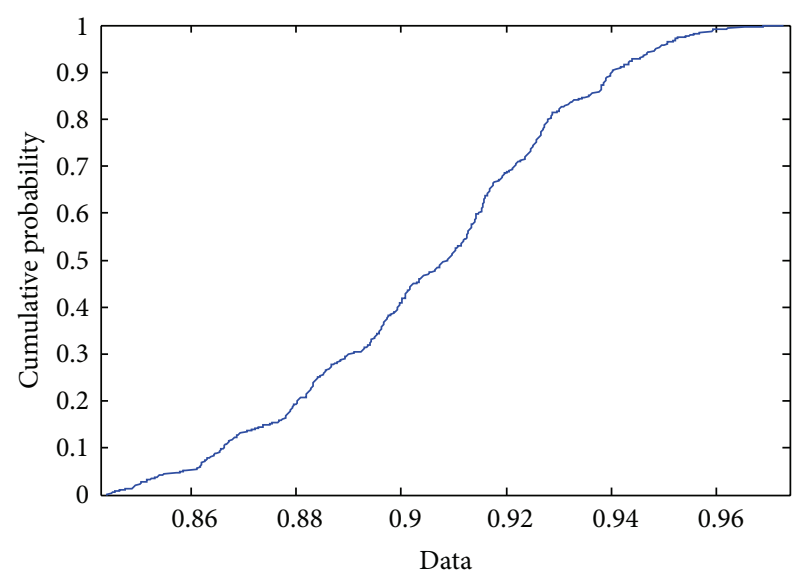

- (DoB)hs data

(a)

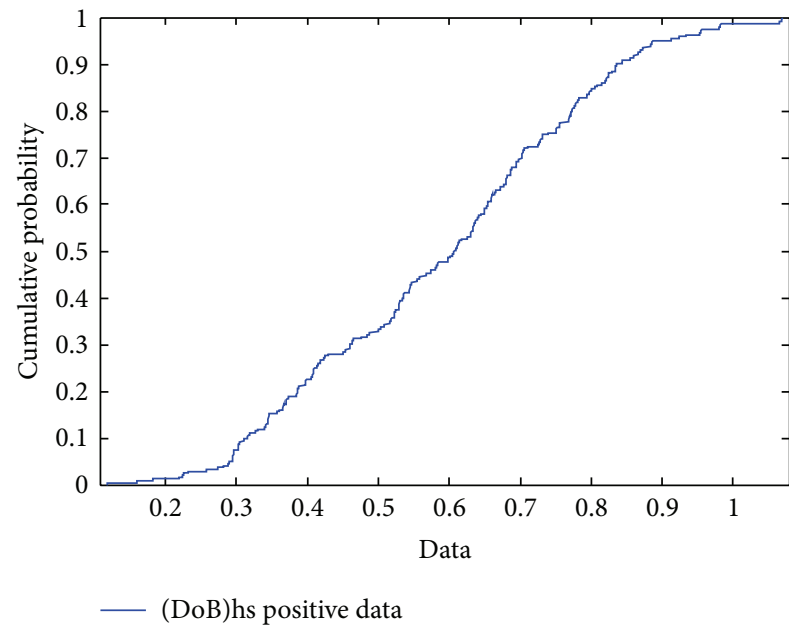

(c)

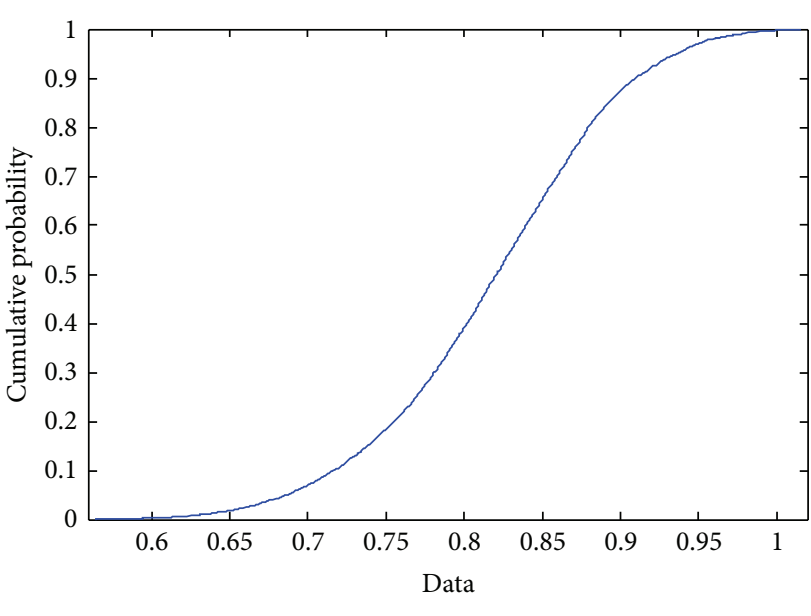

(DoB)hs negative data

(b)

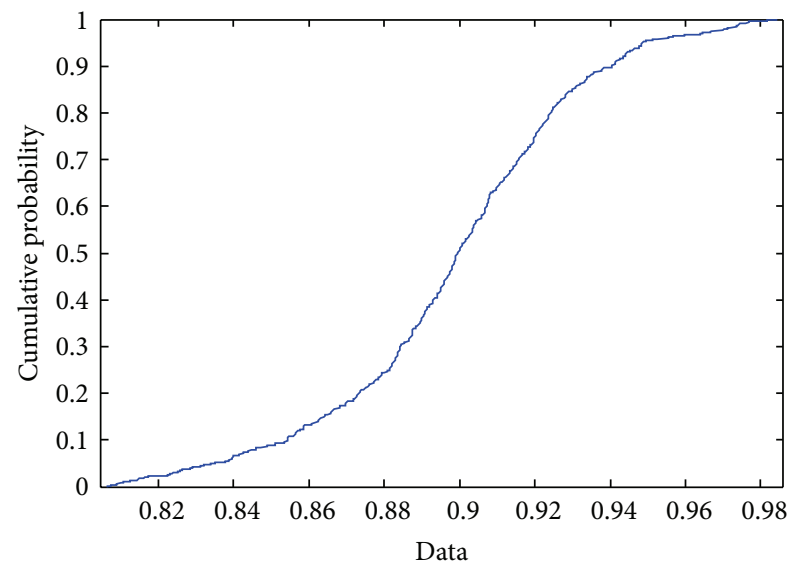

(DoB)hs data

(d)

FIgURE 6: Empirical CDFs for generated DoB samples: (a) $\mathrm{DoB}_{\mathrm{S}-\mathrm{OPB}}$, (b) $\mathrm{DoB}^{-}{ }_{\mathrm{D}-\mathrm{IPB}}$, (c) $\mathrm{DoB}^{+}{ }_{\mathrm{D}-\mathrm{IPB}}$, and (d) $\mathrm{DoB}_{\mathrm{D}-\mathrm{OPB}}$.

For example, empirical CDFs for $\mathrm{DoB}_{\mathrm{S}-\mathrm{OPB}}$, $\mathrm{DoB}^{-}{ }_{\mathrm{D}-\mathrm{IPB}}$, $\mathrm{DoB}^{+}{ }_{\mathrm{D}-\mathrm{IPB}}$, and $\mathrm{DoB}_{\mathrm{D}-\mathrm{OPB}}$ samples have been shown in Figure 6.

Let $F_{0}(x)$ denote a completely specified theoretical continuous CDF. The null hypothesis $H_{0}$ is that the true CDF of $X$ is the same as $F_{0}(x)$. That is, under the null hypothesis,

$$
\lim _{n \rightarrow \infty} \operatorname{Pr}\left[F_{n}(x)=F_{0}(x)\right]=1 .
$$

The test criterion is the maximum absolute difference between $F_{n}(x)$ and $F_{0}(x)$, formally defined as

$$
D_{n}=\sup _{x}\left|F_{n}(x)-F_{0}(x)\right| \text {. }
$$

Theoretical continuous CDFs fitted to the empirical distribution functions of $\mathrm{DoB}_{\mathrm{S}-\mathrm{OPB}}, \mathrm{DoB}^{-}{ }_{\mathrm{D}-\mathrm{IPB}}, \mathrm{DoB}^{+}{ }_{\mathrm{D}-\mathrm{IPB}}$, and $\mathrm{DoB}_{\mathrm{D}-\mathrm{OPB}}$ samples have been shown in Figure 7.

A large value of this statistic $\left(D_{n}\right)$ indicates a poor fit. Hence, the acceptable values must be known. The critical values $D_{n, \xi}$ for large samples, say $n>35$, are $(1.3581 / \sqrt{n})$ and
$(1.6276 / \sqrt{n})$ for $\xi=0.05$ and 0.01 , respectively [16] where $\xi$ is the level of significance in hypothesis testing.

Results of Kolmogorov-Smirnov test for $\mathrm{DoB}_{\mathrm{S}-\mathrm{OPB}}$, $\mathrm{DoB}^{-}{ }_{\text {D-IPB }}, \mathrm{DoB}^{+}{ }_{\mathrm{D}-\mathrm{IPB}}$, and $\mathrm{DoB}_{\mathrm{D}-\mathrm{OPB}}$ samples are given in Tables 3-6, respectively. It should be noted that, according to the results of Kolmogorov-Smirnov test, none of considered continuous CDFs was acceptably fitted to the $\mathrm{DoB}^{-}{ }_{\text {S-IPB }}$ and $\mathrm{DoB}^{+}$S-IPB samples. Hence, no table is provided here for these two samples.

It is evident in Tables 3-6 that Beta, Generalized Extreme Value, Weibull, and Logistic distributions have the smallest values of test statistic for $\mathrm{DoB}_{\mathrm{S}-\mathrm{OPB}}, \mathrm{DoB}^{-}{ }_{\mathrm{D}-\mathrm{IPB}}, \mathrm{DoB}^{+}{ }_{\mathrm{D}-\mathrm{IPB}}$, and $\mathrm{DoB}_{\mathrm{D}-\mathrm{OPB}}$ samples, respectively.

\section{Developed Probability Models for DoBs}

Based on the results of Kolmogorov-Smirnov goodness-of-fit test (Tables 3-6), it can be concluded that Beta, Generalized Extreme Value, Weibull, and Logistic distributions are the 

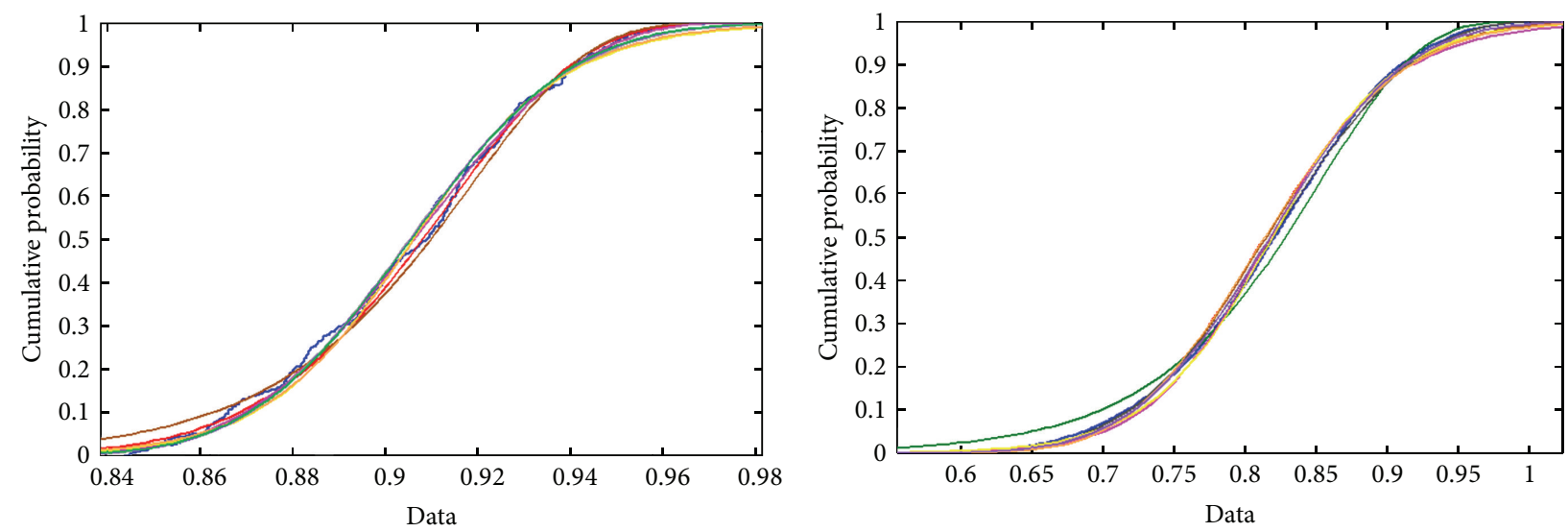

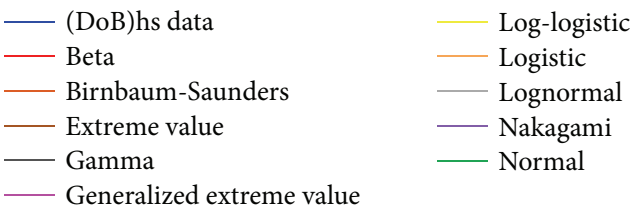

(a)

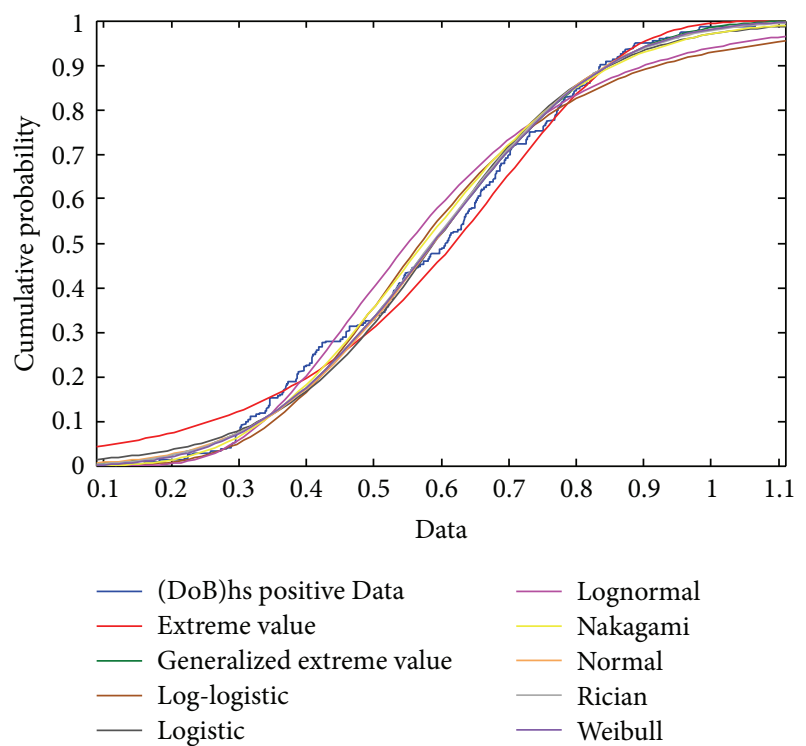

(c)
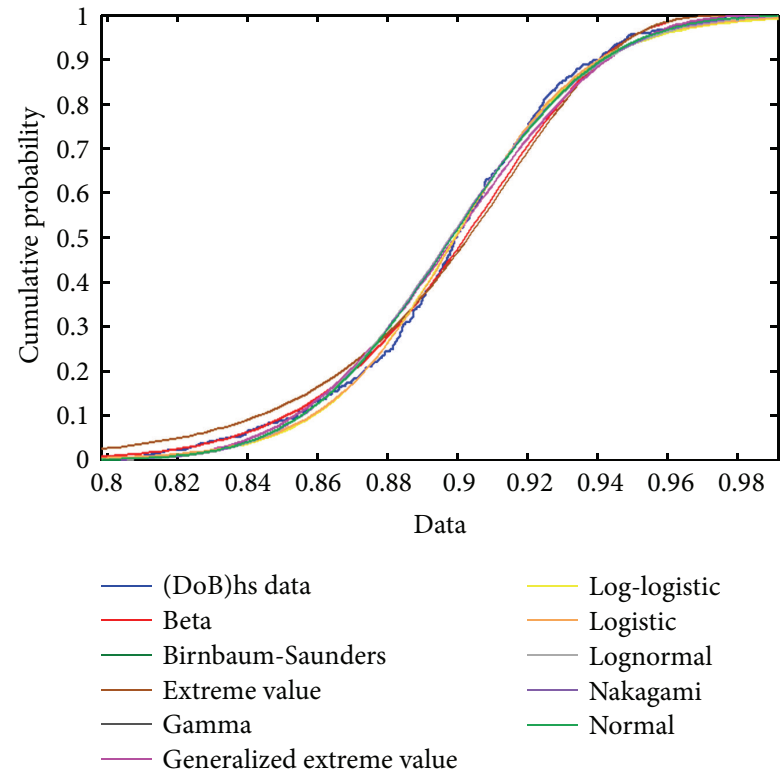

(d)

Figure 7: Theoretical CDFs fitted to the empirical CDFs of DoB samples: (a) DoB S-OPB , (b) DoB $^{-}{ }_{\text {D-IPB }}$, (c) DoB ${ }^{+}{ }_{\text {-IPB }}$, and (d) DoB ${ }_{\text {D-OPB }}$.

best probability models for $\mathrm{DoB}_{\mathrm{S}-\mathrm{OPB}}, \mathrm{DoB}^{-}{ }_{\mathrm{D}-\mathrm{IPB}}, \mathrm{DoB}^{+}{ }_{\mathrm{D}-\mathrm{IPB}}$, and $\mathrm{DoB}_{\mathrm{D}-\mathrm{OPB}}$ in tubular $\mathrm{X}$-joints under bending loads, respectively. The PDFs of these distributions are given by the following equations:

$$
\begin{gathered}
f_{X}(x)=\frac{\Gamma(a+b)}{\Gamma(a) \Gamma(b)} x^{a-1}(1-x)^{b-1} \text { (Beta distribution), } \\
f_{X}(x)=\frac{1}{\sigma} \exp \left[-\left(1+k \frac{x-\mu}{\sigma}\right)^{-1 / k}\right]\left(1+k \frac{x-\mu}{\sigma}\right)^{-1-1 / k}
\end{gathered}
$$$$
f_{X}(x)=\frac{k}{\lambda}\left(\frac{x}{\lambda}\right)^{k-1} \exp \left[-\left(\frac{x}{\lambda}\right)^{k}\right] ; \quad x \geq 0
$$

(Weibull distribution),

$$
f_{X}(x)=\frac{\exp (-(x-\mu) / s)}{s(1+\exp (-(x-\mu) / s))^{2}}
$$

(Generalized Extreme Value distribution), 

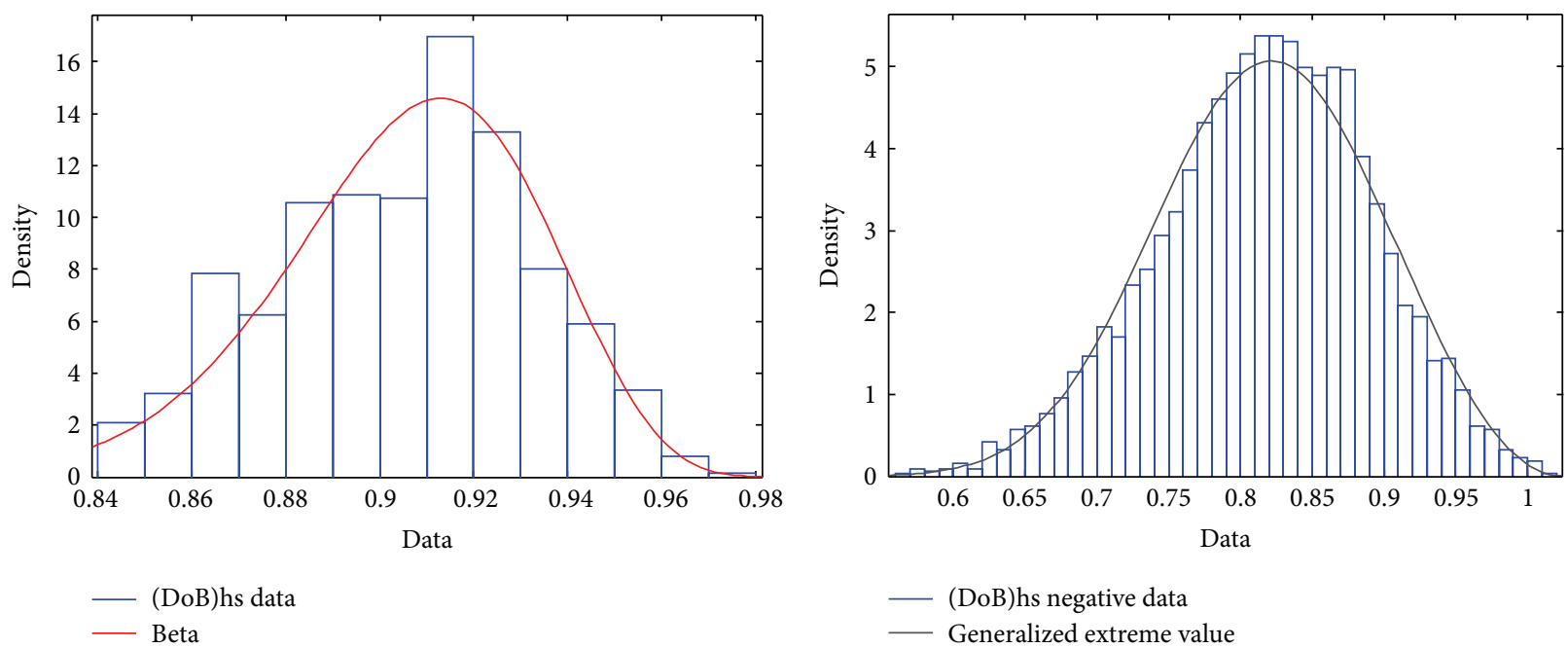

(a)

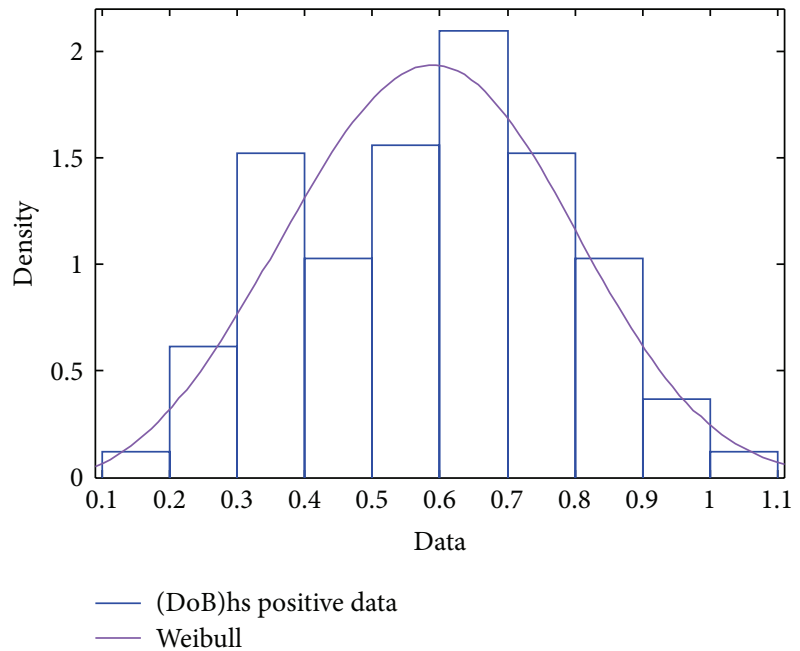

(c)

(b)

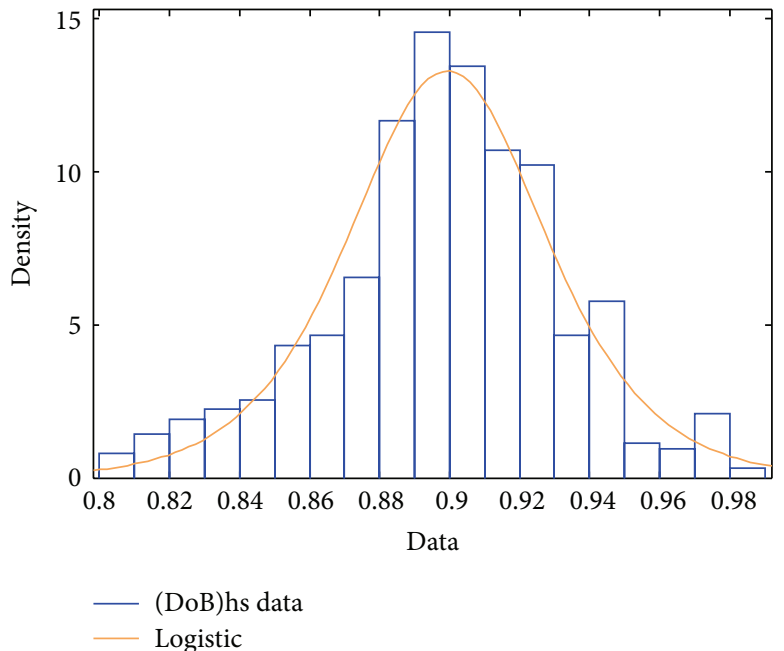

(d)

Figure 8: Proposed PDFs for the DoB values in tubular X-joints subjected to the bending loads: (a) DoB $\mathrm{B}_{\mathrm{S}-\mathrm{OPB}}-\mathrm{Beta}$ distribution, (b) $\mathrm{DoB}^{-}{ }_{\text {D-IPB }}$-Generalized Extreme Value distribution, (c) $\mathrm{DoB}^{+}{ }_{\mathrm{D}-\mathrm{IPB}}$ - Weibull distribution, and (d) DoB $\mathrm{D}_{\text {-OpB }}$ - Logistic distribution.

where $\Gamma(a)$ is the Gamma function defined as follows:

$$
\Gamma(a)=\int_{0}^{\infty} e^{-r} r^{a-1} d r
$$

After substituting the values of estimated parameters from Table 2, the following probability density functions are proposed for the $\mathrm{DoB}_{\mathrm{S}-\mathrm{OPB}}, \mathrm{DoB}^{-}{ }_{\mathrm{D}-\mathrm{IPB}}, \mathrm{DoB}^{+}{ }_{\mathrm{D}-\mathrm{IPB}}$, and $\mathrm{DoB}_{\mathrm{D}-\mathrm{OPB}}$ in tubular X-joints subjected to bending loads:

$$
\begin{aligned}
& f_{X}(x)=\left(5.9328 \times 10^{14}\right) x^{96.8619}(1-x)^{9.2226}\left(\mathrm{DoB}_{\mathrm{S}-\mathrm{OPB}}\right) \text {, } \\
& f_{X}(x)=12.9527 \exp \left[(4.2938 x-4.4022)^{3.0166}\right] \\
& \cdot(4.4022-4.2938 x)^{2.01660}\left(\mathrm{DoB}^{-}{ }_{\mathrm{D}-\mathrm{IPB}}\right) \text {, }
\end{aligned}
$$

$$
\begin{aligned}
f_{X}(x)= & 5.0026\left(\frac{x}{0.657831}\right)^{2.29088} \\
& \cdot \exp \left[-\left(\frac{x}{0.657831}\right)^{3.29088}\right] ; \quad x \geq 0
\end{aligned}
$$$$
\left(\mathrm{DoB}^{+}{ }_{\mathrm{D}-\mathrm{IPB}}\right) \text {, }
$$

$$
\begin{aligned}
& f_{X}(x) \\
& =\frac{\exp (-(x-0.899405) / 0.0187924)}{0.0187924(1+\exp (-(x-0.899405) / 0.0187924))^{2}} \\
& \left(\mathrm{DoB}_{\mathrm{D}-\mathrm{OPB}}\right) .
\end{aligned}
$$

Developed PDFs, shown in Figure 8, can be adapted in the fatigue reliability analysis of tubular X-joints commonly 
TABLE 2: Estimated parameters of PDFs fitted to the density histograms of DoB samples.

\begin{tabular}{|c|c|c|c|c|c|c|c|}
\hline \multirow{2}{*}{ Fitted PDF } & \multirow{2}{*}{ Parameters } & \multicolumn{6}{|c|}{ Estimated values } \\
\hline & & $\mathrm{DoB}_{\text {S-IPB }}^{-}$ & $\mathrm{DoB}_{\mathrm{S}-\mathrm{IPB}}$ & $\mathrm{DoB}_{\mathrm{S}-\mathrm{OPB}}$ & $\mathrm{DoB}_{\text {D-IPB }}^{-}$ & $\mathrm{DoB}_{\text {D-IPB }}^{+}$ & $\mathrm{DoB}_{\mathrm{D}-\mathrm{OPB}}$ \\
\hline Birnbaum-Saunders & $\begin{array}{l}\beta_{0} \\
\gamma_{0}\end{array}$ & & & $\begin{array}{c}0.90498 \\
0.0303296\end{array}$ & $\begin{array}{l}0.813539 \\
0.093508\end{array}$ & - & $\begin{array}{r}0.897649 \\
0.037795\end{array}$ \\
\hline Extreme value & $\begin{array}{c}\mu \\
\sigma\end{array}$ & & & $\begin{array}{c}0.91884 \\
0.0251115\end{array}$ & $\begin{array}{c}0.853587 \\
0.0693142\end{array}$ & $\begin{array}{r}0.688765 \\
0.190828\end{array}$ & $\begin{array}{c}0.91473 \\
0.0318889\end{array}$ \\
\hline Gamma & $\begin{array}{l}a \\
b\end{array}$ & & & $\begin{array}{c}1089.95 \\
0.000830676\end{array}$ & $\begin{array}{c}116.665 \\
0.0070038\end{array}$ & - & $\begin{array}{c}704.135 \\
0.00127574\end{array}$ \\
\hline Generalized extreme value & $\begin{array}{l}k \\
\sigma \\
\mu\end{array}$ & & & $\begin{array}{r}-0.342762 \\
0.0280815 \\
0.896484\end{array}$ & $\begin{array}{c}-0.331497 \\
0.0772041 \\
0.79235\end{array}$ & $\begin{array}{c}-0.286603 \\
0.19848 \\
0.518683\end{array}$ & $\begin{array}{c}-0.325209 \\
0.0350571 \\
0.887031\end{array}$ \\
\hline Log-logistic & $\begin{array}{c}\mu \\
s\end{array}$ & & & $\begin{array}{c}-0.0988711 \\
0.0177489\end{array}$ & $\begin{array}{c}-0.201561 \\
0.05286\end{array}$ & $\begin{array}{l}-0.56315 \\
0.219722\end{array}$ & $\begin{array}{c}-0.106302 \\
0.0209965\end{array}$ \\
\hline Logistic & $\begin{array}{l}\mu \\
s\end{array}$ & - & - & $\begin{array}{l}0.906074 \\
0.0160357\end{array}$ & $\begin{array}{c}0.819049 \\
0.0427215\end{array}$ & $\begin{array}{c}0.590133 \\
0.118319\end{array}$ & $\begin{array}{l}0.899405 \\
0.0187924\end{array}$ \\
\hline Lognormal & $\begin{array}{c}\mu \\
\sigma\end{array}$ & & & $\begin{array}{c}-0.0998412 \\
0.0303511\end{array}$ & $\begin{array}{r}-0.206291 \\
0.0934124\end{array}$ & $\begin{array}{c}-0.596375 \\
0.386297\end{array}$ & $\begin{array}{r}-0.107973 \\
0.0378179\end{array}$ \\
\hline Nakagami & $\begin{array}{l}\mu \\
\Omega\end{array}$ & & & $\begin{array}{c}273.263 \\
0.820492\end{array}$ & - & $\begin{array}{c}2.2093 \\
0.386864\end{array}$ & $\begin{array}{l}177.064 \\
0.80806\end{array}$ \\
\hline Normal (Gaussian) & $\begin{array}{c}\mu \\
\sigma\end{array}$ & & & $\begin{array}{l}0.905396 \\
0.0273892\end{array}$ & $\begin{array}{l}0.817095 \\
0.074663\end{array}$ & $\begin{array}{l}0.589015 \\
0.200225\end{array}$ & $\begin{array}{c}0.89829 \\
0.0337215\end{array}$ \\
\hline Beta & $\begin{array}{l}a \\
b\end{array}$ & & & $\begin{array}{l}97.8619 \\
10.2226\end{array}$ & - & - & $\begin{array}{c}64.4534 \\
7.29193\end{array}$ \\
\hline Rician & $\begin{array}{l}s \\
\sigma\end{array}$ & & & - & $\begin{array}{c}0.813649 \\
0.0748107\end{array}$ & $\begin{array}{r}0.546732 \\
0.209701\end{array}$ & - \\
\hline Weibull & $\begin{array}{l}\lambda \\
k\end{array}$ & & & - & - & $\begin{array}{c}0.657831 \\
3.29088\end{array}$ & - \\
\hline
\end{tabular}

TABLE 3: Results of Kolmogorov-Smirnov goodness-of-fit test for $\mathrm{DoB}_{\mathrm{S} \text {-OPB }}$ sample.

\begin{tabular}{|c|c|c|c|c|c|}
\hline \multirow{2}{*}{ Fitted distribution } & \multirow{2}{*}{ Test statistic } & \multicolumn{2}{|c|}{ Critical value } & \multicolumn{2}{|c|}{ Test result } \\
\hline & & $\xi=0.05$ & $\xi=0.01$ & $\xi=0.05$ & $\xi=0.01$ \\
\hline Birnbaum-Saunders & 0.0613 & \multirow{10}{*}{0.0541} & \multirow{10}{*}{0.0648} & Reject & Accept \\
\hline Extreme value & 0.0515 & & & Accept & Accept \\
\hline Gamma & 0.0596 & & & Reject & Accept \\
\hline Generalized extreme value & 0.0425 & & & Accept & Accept \\
\hline Log-logistic & 0.0547 & & & Reject & Reject \\
\hline Logistic & 0.0521 & & & Accept & Accept \\
\hline Lognormal & 0.0612 & & & Reject & Accept \\
\hline Nakagami & 0.0723 & & & Reject & Accept \\
\hline Normal (Gaussian) & 0.0578 & & & Reject & Reject \\
\hline Beta & 0.0404 & & & Accept & Accept \\
\hline
\end{tabular}

found in offshore jacket structures subjected to bending loads.

\section{Conclusions}

In the present paper, results of parametric equations available for the calculation of the DoB were used to propose probability distribution models for the DoB in the chord member of tubular X-joints subjected to four different types of bending loads including single and double IPB and OPB loadings. Based on a parametric study, a set of samples was prepared and density histograms were generated for these samples using Freedman-Diaconis method. Twelve different PDFs were fitted to these histograms. The ML method was used to determine the parameters of fitted distributions. In each case, Kolmogorov-Smirnov test was used to evaluate the goodness of fit. Based on the results of this test, it was concluded that Beta, Generalized Extreme Value, Weibull, and Logistic distributions are the best probability models for the $\mathrm{DoB}_{\mathrm{S}-\mathrm{OPB}}, \mathrm{DoB}^{-}{ }_{\mathrm{D}-\mathrm{IPB}}, \mathrm{DoB}^{+}{ }_{\mathrm{D}-\mathrm{IPB}}$, and $\mathrm{DoB}_{\mathrm{D}-\mathrm{OPB}}$ in tubular X-joints under bending loads, respectively. Finally, after substituting the values of estimated parameters in distribution models, a set of fully defined PDFs were proposed for the DoB in tubular X-joints subjected to the bending loads. 
TABLE 4: Results of Kolmogorov-Smirnov goodness-of-fit test for $\mathrm{DoB}^{-}{ }_{\mathrm{D}-\mathrm{IPB}}$ sample.

\begin{tabular}{|c|c|c|c|c|c|}
\hline \multirow{2}{*}{ Fitted distribution } & \multirow{2}{*}{ Test statistic } & \multicolumn{2}{|c|}{ Critical value } & \multicolumn{2}{|c|}{ Test result } \\
\hline & & $\xi=0.05$ & $\xi=0.01$ & $\xi=0.05$ & $\xi=0.01$ \\
\hline Birnbaum-Saunders & 0.0411 & & & Reject & Reject \\
\hline Extreme value & 0.0435 & & & Reject & Reject \\
\hline Gamma & 0.0344 & & & Reject & Reject \\
\hline Generalized extreme value & 0.0185 & & & Accept & Accept \\
\hline Log-logistic & 0.0278 & 0.0242 & 0.0291 & Reject & Accept \\
\hline Logistic & 0.0235 & & & Accept & Accept \\
\hline Lognormal & 0.0408 & & & Reject & Reject \\
\hline Normal (Gaussian) & 0.0221 & & & Accept & Accept \\
\hline Rician & 0.0221 & & & Accept & Accept \\
\hline
\end{tabular}

TABLE 5: Results of Kolmogorov-Smirnov goodness-of-fit test for $\mathrm{DoB}^{+}{ }_{\mathrm{D}-\mathrm{IPB}}$ sample.

\begin{tabular}{|c|c|c|c|c|c|}
\hline \multirow{2}{*}{ Fitted distribution } & \multirow{2}{*}{ Test statistic } & \multicolumn{2}{|c|}{ Critical value } & \multicolumn{2}{|c|}{ Test result } \\
\hline & & $\xi=0.05$ & $\xi=0.01$ & $\xi=0.05$ & $\xi=0.01$ \\
\hline Extreme value & 0.0746 & & & Accept & Accept \\
\hline Generalized extreme value & 0.0666 & & & Accept & Accept \\
\hline Log-logistic & 0.0811 & & & Accept & Accept \\
\hline Logistic & 0.0788 & & & Accept & Accept \\
\hline Lognormal & 0.1062 & 0.0864 & 0.1037 & Reject & Reject \\
\hline Nakagami & 0.0721 & & & Accept & Accept \\
\hline Normal (Gaussian) & 0.0710 & & & Accept & Accept \\
\hline Rician & 0.0671 & & & Accept & Accept \\
\hline Weibull & 0.0660 & & & Accept & Accept \\
\hline
\end{tabular}

TABLE 6: Results of Kolmogorov-Smirnov goodness-of-fit test for DoB $\mathrm{D}_{\text {-OPB }}$ sample.

\begin{tabular}{|c|c|c|c|c|c|}
\hline \multirow{2}{*}{ Fitted distribution } & \multirow{2}{*}{ Test statistic } & \multicolumn{2}{|c|}{ Critical value } & \multicolumn{2}{|c|}{ Test result } \\
\hline & & $\xi=0.05$ & $\xi=0.01$ & $\xi=0.05$ & $\xi=0.01$ \\
\hline Birnbaum-Saunders & 0.0650 & \multirow{10}{*}{0.0541} & \multirow{10}{*}{0.0648} & Reject & Reject \\
\hline Extreme value & 0.0721 & & & Reject & Reject \\
\hline Gamma & 0.0628 & & & Reject & Accept \\
\hline Generalized extreme value & 0.0611 & & & Reject & Accept \\
\hline Log-logistic & 0.0315 & & & Accept & Accept \\
\hline Logistic & 0.0284 & & & Accept & Accept \\
\hline Lognormal & 0.0651 & & & Reject & Reject \\
\hline Nakagami & 0.0608 & & & Reject & Accept \\
\hline Normal (Gaussian) & 0.0588 & & & Reject & Accept \\
\hline Beta & 0.0587 & & & Reject & Accept \\
\hline
\end{tabular}

\section{Conflict of Interests}

The authors declare that there is no conflict of interests regarding the publication of this paper.

\section{References}

[1] M. P. M. Connolly, A fracture mechanics approach to the fatigue assessment of tubular welded $Y$ and K-joints [Ph.D. thesis], University College London, London, UK, 1986.
[2] D. Bowness and M. M. K. Lee, "Fatigue crack curvature under the weld toe in an offshore tubular joint," International Journal of Fatigue, vol. 20, no. 6, pp. 481-490, 1998.

[3] C. K. Lee, L. S. Tjhen, S. P. Chiew, and S. Yongbo, "Numerical models verification of cracked tubular T, Y and $\mathrm{K}$-joints under combined loads," Engineering Fracture Mechanics, vol. 72, no. 7, pp. 983-1009, 2005.

[4] Y.-B. Shao, "Analysis of stress intensity factor (SIF) for cracked tubular K-joints subjected to balanced axial load," Engineering Failure Analysis, vol. 13, no. 1, pp. 44-64, 2006. 
[5] A. C. Wordsworth and G. P. Smedley, "Stress concentrations at unstiffened tubular joints," in Proceedings of the European Offshore Steels Research Seminar, Paper 31, Cambridge, UK, 1978.

[6] M. Efthymiou, "Development of SCF formulae and generalized influence functions for use in fatigue analysis," in Proceedings of the Offshore Tubular Joints Conference (OTJ '88), Surrey, UK, 1988.

[7] E. Chang and W. D. Dover, "Parametric equations to predict stress distributions along the intersection of tubular X and DTjoints," International Journal of Fatigue, vol. 21, no. 6, pp. 619$635,1999$.

[8] M. A. Lotfollahi-Yaghin and H. Ahmadi, "Geometric stress distribution along the weld toe of the outer brace in two-planar tubular DKT-joints: parametric study and deriving the SCF design equations," Marine Structures, vol. 24, no. 3, pp. 239-260, 2011.

[9] H. Ahmadi and M. A. Lotfollahi-Yaghin, "Geometrically parametric study of central brace SCFs in offshore three-planar tubular KT-joints," Journal of Constructional Steel Research, vol. 71, pp. 149-161, 2012.

[10] H. Ahmadi, M. A. Lotfollahi-Yaghin, and S. Yong-Bo, "Chordside SCF distribution of central brace in internally ringstiffened tubular KT-joints: a geometrically parametric study," Thin-Walled Structures, vol. 70, pp. 93-105, 2013.

[11] E. Chang and W. D. Dover, "Prediction of degree of bending in tubular X and DT joints," International Journal of Fatigue, vol. 21, no. 2, pp. 147-161, 1999.

[12] M. R. Morgan and M. M. K. Lee, "Prediction of stress concentrations and degrees of bending in axially loaded tubular K-joints," Journal of Constructional Steel Research, vol. 45, no. 1, pp. 67-97, 1998.

[13] UK Department of Energy (DoE), Background to New Fatigue Design Guidance for Steel Joints and Connections in Offshore Structures, UK Department of Energy (DoE), London, UK, 1995.

[14] M. M. K. Lee and D. Bowness, "Estimation of stress intensity factor solutions for weld toe cracks in offshore tubular joints," International Journal of Fatigue, vol. 24, no. 8, pp. 861-875, 2002.

[15] W. Shen and Y. S. Choo, "Stress intensity factor for a tubular T-joint with grouted chord," Engineering Structures, vol. 35, pp. 37-47, 2012.

[16] N. T. Kottegoda and R. Rosso, Applied Statistics for Civil and Environmental Engineers, Blackwell Publishing, Southampton, UK, 2nd edition, 2008. 

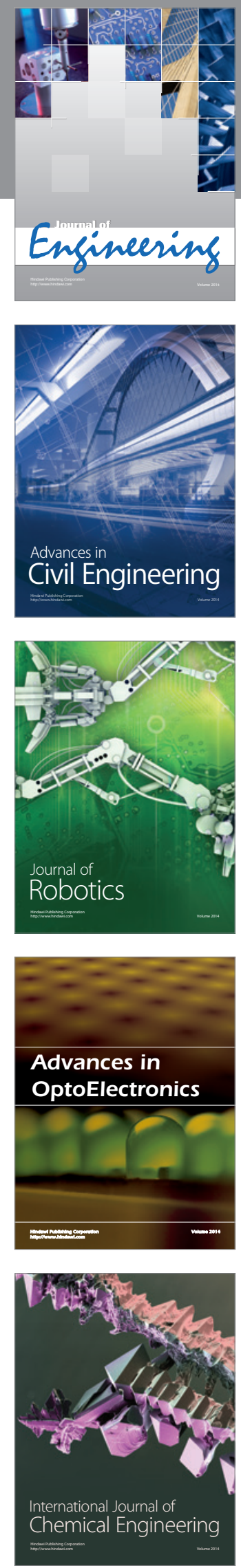

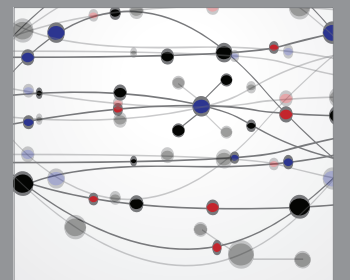

The Scientific World Journal
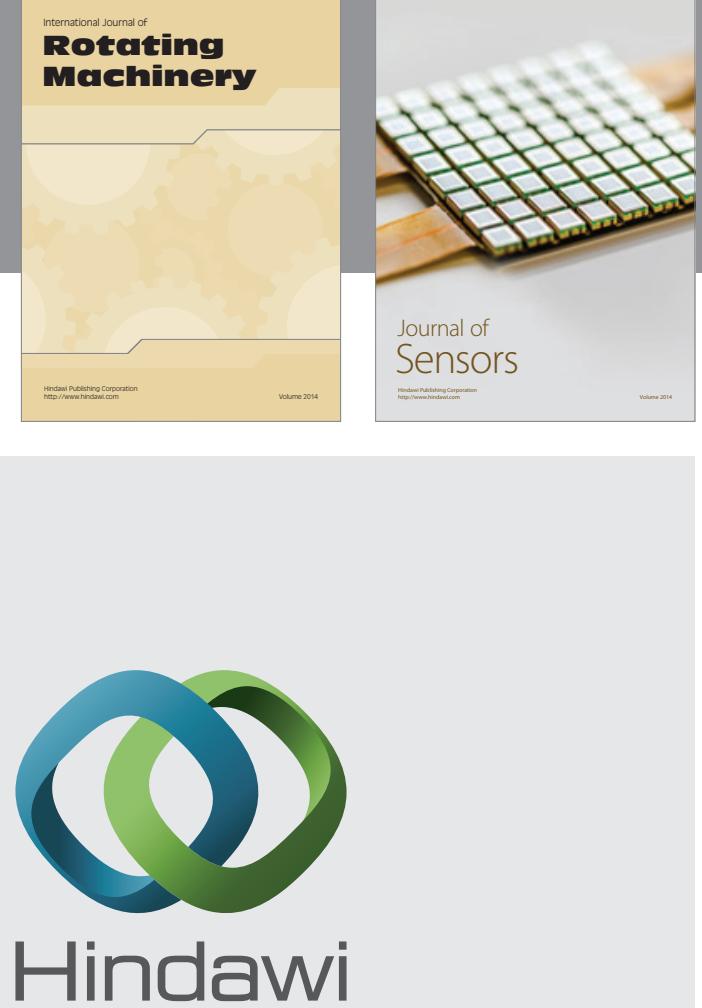

Submit your manuscripts at http://www.hindawi.com
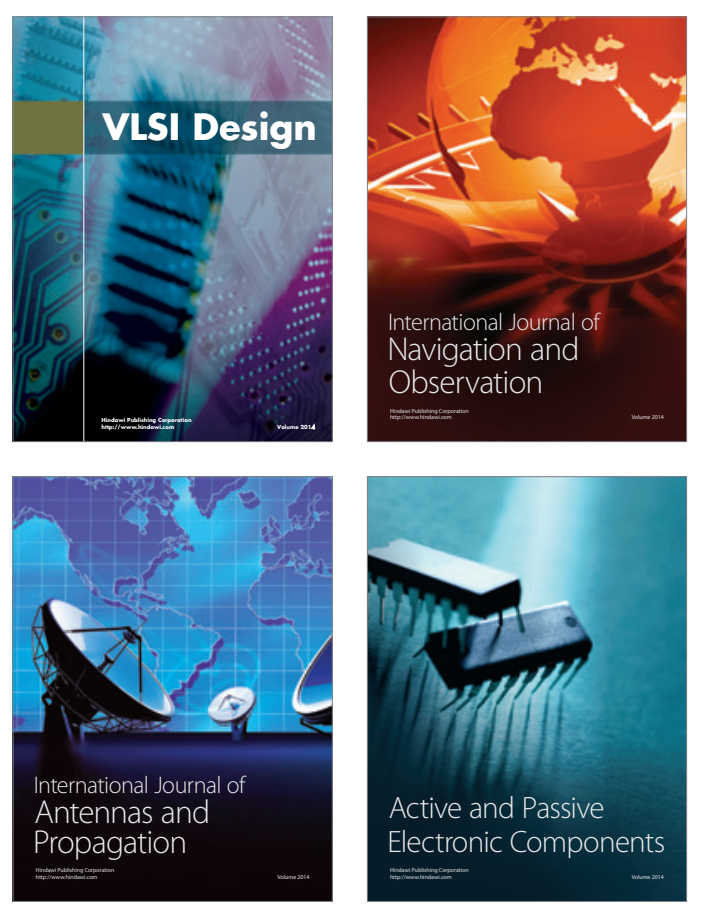
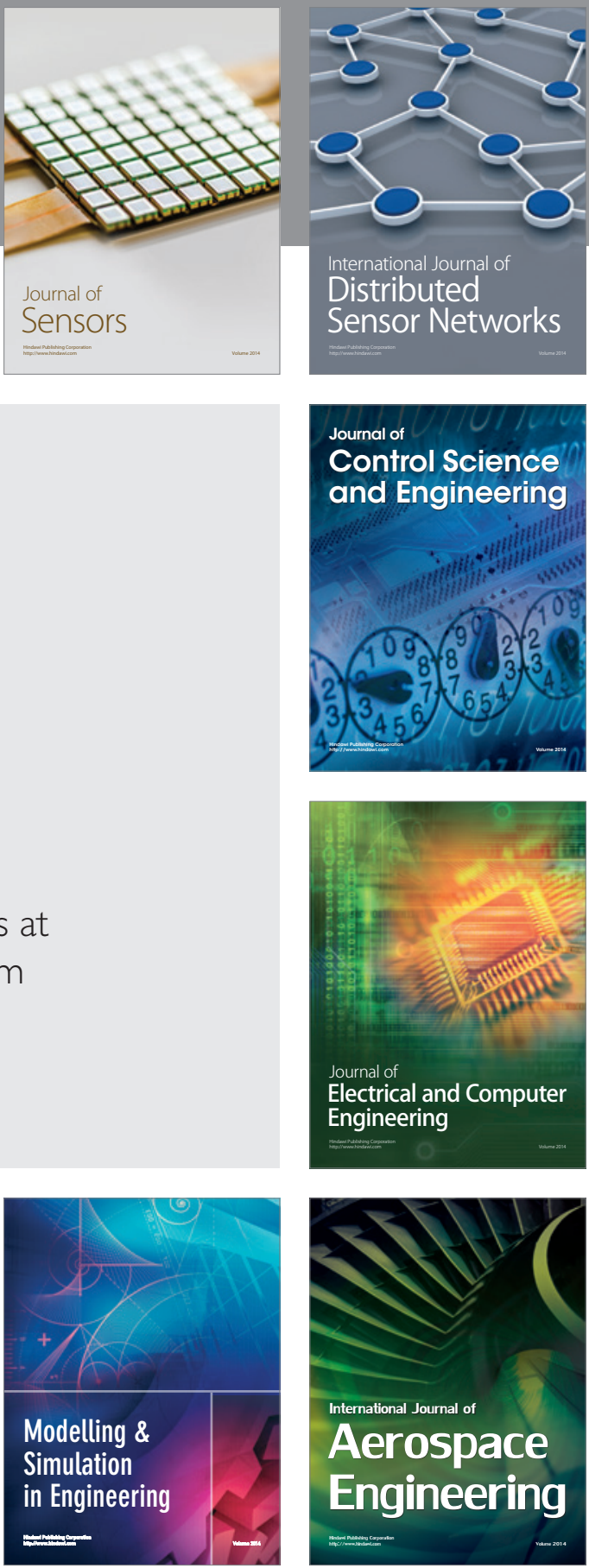

Journal of

Control Science

and Engineering
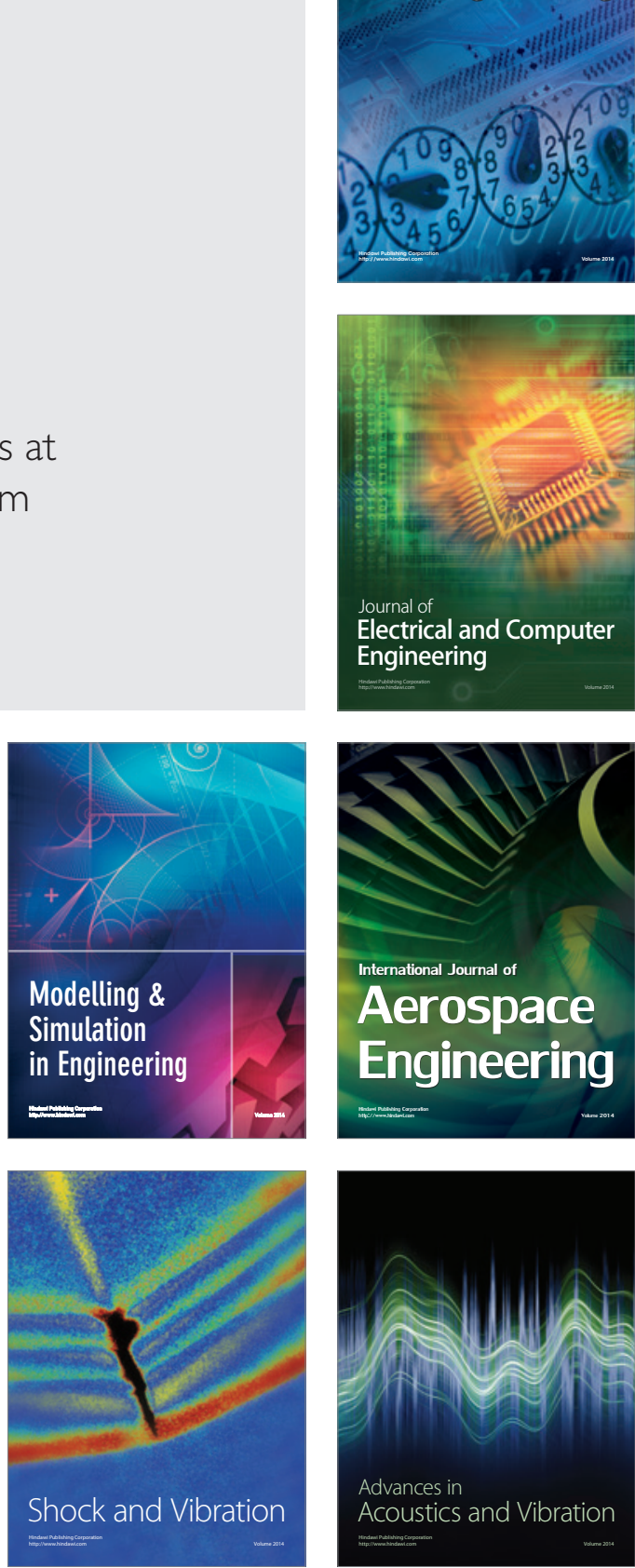